\title{
Pragmatism and Political Pluralism
}

\section{Michele Marsonet}

\section{(2) OpenEdition \\ Journals}

Electronic version

URL: http://journals.openedition.org/ejpap/968

DOI: $10.4000 /$ ejpap.968

ISSN: 2036-4091

Publisher

Associazione Pragma

\section{Electronic reference}

Michele Marsonet, «Pragmatism and Political Pluralism », European Journal of Pragmatism and American Philosophy [Online], I-1/2 | 2009, Online since 01 July 2009, connection on 10 December 2020. URL : http://journals.openedition.org/ejpap/968 ; DOI : https://doi.org/10.4000/ejpap.968

This text was automatically generated on 10 December 2020 .

\section{(c) $(1)$}

Author retains copyright and grants the European Journal of Pragmatism and American Philosophy right of first publication with the work simultaneously licensed under a Creative Commons AttributionNonCommercial-NoDerivatives 4.0 International License. 


\title{
Pragmatism and Political Pluralism
}

\author{
Michele Marsonet
}

1 Pragmatists always had clear ideas about the relations between the natural and the social worlds. Most of them tell us, first of all, that human beings have evolved within nature as creatures that solve their survival problems through intelligence. The emergence of intelligence, on the other hand, must not be seen as a purpose of nature itself, but rather as our functional version of survival mechanisms such as physical force or numerousness. The systematic use of this intelligence in a context which is eminently social and communicative creates - through cultural evolution - a methodology of rational inquiry that enables us to develop, and test, cognitive models of the real to explain the structure of our experience. No doubt our science is the best instantiation of these cognitive models, but pragmatist thinkers, unlike the positivists old and new, by no means claim that it is also the completion of this work. Other responses are always required. In particular, we must create a sort of "superstructure" made up of values, many of which (i.e., cognitive values like coherence, comprehensiveness, simplicity, etc.) are useful instruments within the cognitive project itself. This explains why, for instance, economic considerations are certainly important in the conduct of our cognitive affairs.

2 However, when it comes to conducting our socio-political affairs, ${ }^{1}$ these values, which can always be tested pragmatically, are also under determined. In other words, they do not lead to a specific and exact resolution of the issues at stake, but leave rather room for alternative and competing ways of conducting our inter-personal affairs. This means that abstract rationality alone is insufficient to enforce a consensus on social issues, and on a larger scale, ideological and political issues as well. The problem is that, on the purely theoretical side, such dissonance has no dramatic consequences. But on the practical side of public policy, any attempt to achieve resolution on these issues can have - and many times actually has - unfortunate consequences by way of producing conflicts. This should explain well enough why the criticism of all theories based on consensus is the starting point of many pragmatists' social and political philosophy.

3 Nicholas Rescher, for example, deems the idea that social harmony must be predicated in consensus to be both dangerous and misleading. Rather, he argues that an essential 
problem of our time is the creation of political and social institutions that enable people to live together in peaceful and productive ways, despite the presence of ineliminable disagreements about theoretical and practical issues. These remarks, in turn, strictly recall the practical impossibility of settling philosophical disputes by having recourse to abstract and aprioristic principles. In the circumstances, the social model of team members cooperating for a common purpose is unrealistic. A more adequate model is, instead, that of a classical capitalism where - in a sufficiently well developed system both competition and rivalry manage somehow to foster the benefit of the entire community (theory of the "hidden hand"). Certainly the scientific community is one of the best examples of this that we have, although even in this case we must be careful not to give too idealized a picture of scientific research. Rescher, eventually, finds many similarities between the scientific and the business communities:

The pursuit of knowledge in science can play a role akin to that of pursuit of wealth in business transactions. The financial markets in stocks or commodities futures would self- destruct if the principle, my word is my bond, were abrogated, since no one would know whether a trade had actually been made. In just this way, too, the market information would self-destruct if people's truthfulness could not be relied upon. Thus in both cases, unreliable people have to be frozen out and exiled from the community. In cognitive and economic contexts alike, the relevant community uses incentives and sanctions (artificially imposed costs and benefits) to put into place a system where people generally act in a trusting and trustworthy way. Such a system is based on processes of reciprocity that advantage virtually everyone. ${ }^{2}$

Let us ask: why Rescher thinks that the idea of consensus may - and in many cases does cause dangerous consequences? After all consensus, i.e. the uniformity of belief and evaluation, has been considered by many prominent philosophers of the Western tradition as an ideal both good and worth being pursued. Consensus, however, is essentially a matter of agreement, and the fact is that people sometimes agree on various sorts of things and sometimes (or, maybe better, most of the times) do not. At this point we are faced with two basic positions. On the one side (a) the "consensualists" maintain that disagreement should be averted no matter what, while, on the other, (b) the "pluralists" accept disagreement because they take dissensus to be an inevitable feature of the imperfect world in which we live. A pluralistic vision, therefore, tries to make dissensus tolerable, and not to eliminate it. Rescher clearly sides with the pluralistic field, and his pro-pluralism arguments pivot on the following remarks:

The long and short of it is that consensus appertains to rationality as an ideal, not as a realizable 'fact of life.' The points of 'universal agreement among rational people' are not a matter of an ultimately discovered de facto universal consensus people independently predetermined as rational. It is simply a matter of the meaning-standards that we who use this notion impose upon the idea of 'rationality' in the first place. ${ }^{3}$

It follows that we use the concept of "consensus" in a rather circular way. Someone might bona fide believe that he or she is using it in a perfectly neutral manner but, actually, we always use predetermined standards in order to define who a "rational person" is.

Things being so, all theories of idealized consensus present us with serious setbacks. This is the case, for instance, with Charles S. Peirce. As is well known, Peirce takes truth to be "the limit of inquiry," i.e. either what science will discover in the (idealized) long run, or what it would discover if the human efforts were so extended. ${ }^{4}$ By taking this path, thus, truth is nothing but the ultimate consensus reached within the scientific community. We can be sure that, once a "final" answer to a question has been found which is thereafter 
maintained without change, that is the truth we were looking for. This fascinating theory, however, has various unfortunate consequences. What concerns us in this context is that, for Peirce, there really exists an ultimate method of question-resolution which produces results acceptable by everyone and that, furthermore, equates factual truth with a sort of "long-run" consensus. Rescher rightly notes that "for Peirce, science is effectively a latter-day surrogate - a functional equivalent - for the medieval philosopher's conception of the 'mind of God'."'

7 In our day the German philosopher Jürgen Habermas has in a way revived these Peircean insights, putting forward an influential theory to the effect that consensus indeed plays a key role in human praxis, so that the primary task of philosophy is to foster it by eliminating the disagreement which we constantly have to face in the course of our daily life. In his "communicative theory of consensus," furthermore, he claims that human communication rests on an implicit commitment to a sort of "ideal speech situation" which is the normative foundation of agreement in linguistic matters. Consequently, the quest for consensus is a constitutive feature of our nature of (rational) human beings: rationality and consensus are tied together. A very strong consequence derives from Habermas' premises: were we to abandon the search for consensus we would lose rationality, too, and this makes us understand that he views the pursuit of consensus as a regulative principle (rather than as a merely practical objective).

Rescher thus opposes both Peirce's eschatological view and Habermas' regulative and idealized one. To all those authors who contend that science, for example, is a typically consensus-seeking enterprise, he replies that, even in this context, consensus remains an aspiration. Agreement is usually achieved on issues of concrete particularity, but never extends to broader, theoretical domains, because controversy is all too common in the scientific domain. If we take into account Rescher's stance about scientific realism, it may be easily verified that, for him, there is no scientific knowledge as such, but just our scientific knowledge, which turns out to be relativized to the kinds of experience we have. Science always is a two-sided enterprise, in which both nature and experiencing subjects have a fundamental role to play. We may not plausibly assume that the science of different civilizations will significantly resembles ours. But we can proceed even further, by supposing that the very topics of an alien (extraterrestrial) science could differ dramatically from our own, probably due to the fact that they experience nature in quite different ways. After all, we developed electromagnetic theory because our environment provided us with lodestones and electrical storms, but this is not a necessary feature of all natural environment present in the Universe at large. To sum up, we have the following kind of picture:

To what extent would the functional equivalent of natural science built up by the inquiring intelligences of an astronomically remote civilization be bound to resemble our science? To begin with, the machinery of formulation used in expressing their science might be altogether different. Specifically, their mathematics might be very unlike ours. Their dealings with quantity might be entirely a-numerical purely comparative, for example, rather than quantitative. Especially if their environment is not amply endowed with solid objects or stable structures congenial to measurement - if, for example, they were jellyfish-like creatures swimming about in a soupy sea - their "geometry" could be something rather strange, largely topological, say, and geared to flexible structures rather than fixed sizes or shapes. One's language and thought processes are bound to be closely geared to the world as one experiences it. ${ }^{6}$ 

were discussing above, is instead likely to tell us something important about the problem of consensus. For it is clear that, as we may assumedly "scan" nature in a way partially or totally different from that of hypothetical alien creatures, so we normally "scan" the social world in a way partially or totally different from the other intelligent beings with whom we share it. And this simply is a fact of life that everybody can personally verify, and not a mere theoretical assumption. Right at this level of analysis Rescher finds a good confirmation of a basic thesis of his: conceptualization (and value-endowment as well) is always with us, and forms part and parcel of the world-as-we-know-it. To put it in a slightly different way, cognitive usage of different bodies of experience takes naturally different inquirers to achieve diverse results, so that cognitive dissensus is an inevitable outcome of the experiential diversity among inquirers.

At this point, a theorist of consensus like Habermas might as well reply that, after all, he never meant to deny the presence of disagreement and cognitive dissensus in human society. But it is just because dissensus leads to the enhancement of disorder in the social body that we must try to overcome it, thus transcending the actual course of things. Rescher's position in this regard is that such a transcending step entails the presence of a privileged viewpoint that we do not have at our disposal, so that "truth and consensus converge only in the ideal limit - only when we can contemplate the sort of agreement that would be reached by ideally rational inquirers working under ideally favorable conditions." But such conditions are never given in practical life. In science our discoveries, although theoretically "secured" by the scientific method, constantly need corrections, adjustments and, often, even replacements. Just the same is valid in the practical conduct of our cognitive affairs, where the "ideal inquiry" would require an "ideal rationality" on the part of the inquirers and the absence of limitations on our resources: neither of these two conditions are practically achievable in the concrete world of our actions and deliberations. To use an all-encompassing slogan: We must learn how to live with dissensus, because this is what the normal course of things forces upon us.

11 At this point, an important question still needs to be addressed. One is in fact entitled to ask: Does pluralism lead to skepticism or syncretism? No doubt this is one of the possible outcomes of a pluralistic theory like Rescher's, and our author points out that this possibility has often been exploited in the history of Western philosophy. Leaving aside the ancient skeptics, it is interesting to note that Rescher takes Richard Rorty to be a good representative of the skepticism of our day, since he claims that the standards of the community are the only subjectivity-transcending resource at our disposal. As for syncretism, Rescher observes that Paul Feyerabend's famous motto "anything goes" is the best contemporary example of this trend of thought, according to which men must endorse the whole set of cognitive alternatives they meet in everyday life.

Rescher, instead, sees no direct linkage between pluralism on the one hand, and skepticism or syncretism on the other. Certainly we have no direct access to the absolute Truth, the only path at our disposal being determined by what we conscientiously -

believe. But the fact that other people may think differently from ourselves is no reason for preventing us from having confidence in the correctness of our views; in other words, neither the others' agreement with us nor their disagreement shows that we are actually holding false beliefs. No contradiction shows up between the "defining principles of rationality" and the pluralistic differentiation that stems from the many available 
answers to the question: "What is it rational to do?" The sphere of rationality, in fact, is a flexible structure formed by what Rescher calls a "hierarchy of levels."

We have thus a pluralism without indifferentism, in the sense that "the absence of consensus simply is not - in the very logic of the situation - a decisive impediment to rational validity and impersonal cogency." ${ }^{\prime \prime}$ As long as we see our own position as rationally appropriate and are able to argue in its favor, we must have the courage of our convictions. If one accepts these basic tenets it is all too natural to think that personal positions can indeed by supported by standards of impersonal cogency. Those who take relativism to be a logical and natural consequence of pluralism erroneously think that, given the diversity of the various positions, we cannot choose among them. To the contrary,

A pluralism of potential basis-diversity in rational inquiry is altogether compatible with an absolutistic commitment to our own basis. One can certainly combine a relativistic pluralism of possible alternatives with a monistic position regarding ideal rationality and a firm and reasoned commitment to the standards intrinsic to one's own position. Rational is as rational does - it hinges on the norms, standards, and criteria that we ourselves can endorse as rationally appropriate on the basis of what best qualifies - from where we stand - as a well-considered position as to what is appropriate for anybody. ${ }^{9}$

For sure we must recognize the presence of different perspectives, but on the other hand our experiential indications provide us with criteria for making a rational choice. The fact that no appropriate universal diet exists does not lead to the conclusion that we can eat anything, and the absence of a globally correct language does not mean that we can choose a language at random for communicating with others in a particular context. For these reasons he concludes that "an individual need not be intimidated by the fact of disagreement - it makes perfectly good sense for people to do their rational best towards securing evidentiated beliefs and justifiable choices without undue worry about whether or not others disagree."10

So we are left with the question: To what extent are Rescher's doubts about consensus applicable to the real social and political situations? As it was remarked before, in fact, consensus is deemed by many authors to be a sine qua non condition for achieving a benign political and social order, while its absence is often viewed as a premonitory symptom of chaos. Needless to say the feelings are usually strong in this regard, because political and social philosophy has a more direct impact on our daily life than other such traditional sectors of the philosophical inquiry as, say, metaphysics or epistemology. It might be argued that these latter disciplines' importance for our life is as least as great (although less visible) than that of political philosophy, but this is not our task in the present context.

What deserves to be pointed out now is that the search for consensus has many concrete contraindications, which can mainly be drawn from history. Think, for instance, of how Hitler gained power in Germany in the 1930's. As a matter of fact he obtained a resounding victory through democratic election, because he was able to make the political platform of the Nazi party consensually accepted by a large majority of citizens. It would be foolish, however, to draw the conclusion that Hitler and the Nazis were right just because they were very good consensus-builders. On the contrary, the United States is a good example of a democratically thriving society which can dispense with consensus, and where dissensus is deemed to be productive (at least to a certain extent). Another striking fact is that the former Soviet Union was, instead, a typically consensus- 
seeking society. Dissensus there was severely banned and punished, and that situation matches well Rescher's words:

Not only is insistence on the pursuit of general consensus in practical matters and public affairs unrealistic, it is also counter-productive. For it deprives us of the productive stimulus of competition and the incentive of rivalry. In many situations of human life, people are induced to make their best effort in inquiry or creative activity through rivalry rather than conformity. Productivity, creativity, and the striving for excellence are - as often as not - the offspring of diversity and conflict. Dissensus has this to be said for it, at least, that it is at odds with a stifling orthodoxy. A dissent accommodating society is ipso facto pluralistic, with all the advantages that accrue in situations where no one school of thought is able to push the others aside. ${ }^{11}$

17 By adopting this line of reasoning, the commonsense view about the subject is practically reversed. Homogeneity granted by consensus is not the mark of a benign social order, since this role is more likely to be played by a dissensus-dominated situation which is in turn able to accommodate diversity of opinions. It follows, among other things, that we should be very careful not to characterize the consensus endorsed by majority opinion as intrinsically rational. In the industrialized nations of the Western world the power of the media (especially TV) in building up consensus is notoriously great. It may - and does happen sometimes, however, that the power of the media in assuring consensus is used to support bad politicians, who repay the favor by paying attention to sectorial rather than to general interests. It is thus easily seen that consensus is not an objective that deserves to be pursued no matter what.

18 All this seems plausible and reasonable, despite the fact that many theorists nowadays continue to view consensus an indispensable component of a good and stable social order. It is the case, once again, with Jürgen Habermas. The Marxist roots of Habermas' thought ${ }^{12}$ explain why the German philosopher is so eager to have the activities of the people harmonized thank to their interpersonal agreement about ends and means. The basis of agreement is thus both collective and abstractly universal. Consensus, in Habermas' view, is a pre-requisite for cooperation and the fundamental task of philosophy is to foster it by eliminating the possibility of disagreement. The quest for consensus is so important that its abandonment would make us lose our rationality. What type of consensus, however, are we talking about in this context? It must clearly be a sort of ideal whose pursuit is more an highly idealized and regulative principle than a practical goal. Interestingly enough, Rescher both sees many points of contact (mutatis mutandis, of course) between the aforementioned stance and John Rawls' well known social-contract theory, and many points of difference between Habermas and Rawls on the one side and himself on the other:

A theory geared to utopian assumptions can provide little guidance for real-life conditions. What is needed is, clearly, a process attuned to the suboptimal arrangements of an imperfect reality. A perfectly sensible approach to the rational legitimation of the political process can substitute for the contractual-idealization approach of social-contract theory (Rawls), or ideal-consensus theory of 'discourse ethics' (Habermas and Apel), the older and better-known mechanism of rational decision. And against the 'utopian unrealism' of the contractarian and consensus theorists, the present approach takes the more 'realistic' line of hard-nosed costbenefit economics. ${ }^{13}$

19 Another key word - "acquiescence" - needs at this point be introduced. Given that the insistence on the pre-requisite of communal consensus is simply unrealistic, we must come to terms with concrete situations, i.e. with facts as real life presents us with. If, 
according to contractarian lines of thought, we take justice to be the establishment of arrangements that are (or, even better, would be) reached in idealized conditions, then we cannot help but noting that justice is not a feature of our imperfect world. "Life is unjust" is bound to be our natural conclusion, together with the acknowledgement that real-life politics is the art of the possible. It is obvious as well, however, that even in real-life politics we constantly need to make decisions and to take some course of action. How should we behave, then, given the fact that the so-called communal consensus turned out to be unachievable?

The answer is that a modern and democratic society looks for social accommodation, which means that it always tries to devise methods for letting its members live together in peace even in those - inevitable - cases when a subgroup prevails over another. As Rescher has it,

the choice is not just between the agreement of the whole group or the lordship of some particular subgroup. Accommodation through general acquiescence is a perfectly practicable mode for making decisions in the public order and resolving its conflicts. And, given the realities of the situation in a complex and diversified society, it has significant theoretical and practical advantages over its more radical alternatives. ${ }^{14}$

21 The reader will not find it difficult to recognize that this is just the strategy constantly adopted within the democratic societies of the Western world, which, in turn, distinguishes them from all forms of tyrannies and monocratic forms of government still thriving nowadays on our planet.

Acquiescence is not geared to the necessity of finding agreement with others: its characteristic feature is, rather, the willingness to get on without agreement. Daily life teaches us that, when conditions of reciprocal respect are maintained and enforced by law, we are able to go along with other people even though we do not share their views (and, obviously, vice-versa). We have, in sum, an acquiescence of diversity that makes toleration of others' opinions possible. Unlike John Stuart Mill, Rescher does not take the merit of such tolerance to be a requisite for progress towards the realization of ultimate Truth, but, rather, as a pre-condition for pursuing in peace our own projects. It should be clear, thus, how distant he is from the positions of Francis Fukuyama, who claims that the end of Marxism means the end of history as well, accompanied by the foreseeable final triumph of Western democracy over any other form of political/social organization. ${ }^{15}$ However appealing this kind of democratic messianism may be to the media and the large public, it resembles too closely the Marxist brand of messianism which it took such a long time to defeat.

Acquiescence is thus a matter of mutual restraint, a sort of "live and let live" concrete politics that permits to any individual or subgroup belonging in a larger group to avoid fight in order to gain respect for its own position. Rescher cites in this regard an historical episode that is more helpful than any theoretical definition for understanding the difference between acquiescence and consensus:

Shortly after the end of the Civil War, in early 1866, Robert E. Lee, generalissimo of the just-defeated Confederacy, was asked to testify before a hostile Joint Committee on Reconstruction of the US Congress. Interrogated about the stance of the former secessionists towards Washington's plans and programmes for them, Lee was pressed on whether the Southerners agreed with these and whether 'they are friendly towards the government of the United States'? Choosing his words carefully, Lee replied, 'I believe they entirely acquiesce in the government.' The 
difference between acquiescence and agreement cannot be shown much more clearly.

Thus acquiescence, and not consensual agreement, turns out to be the key factor for building a really democratic society. In a situation like that of the former Yugoslavia, for instance, it would be foolish to ask for consensus given the historical and ethnical roots of the war that was fought. But a search for acquiescence would be much less foolish, with all factions giving up something in order to avoid even greater damages and losses.

If we want to be pluralists in the true spirit of Western democratic thought, we must abandon the quest for a monolithic and rational order, together with the purpose of maximizing the number of people who approve what the government, say, does. On the contrary, we should have in mind an acquiescence-seeking society where the goal is that of minimizing the number of people who strongly disapprove of what is being done. We should never forget, in fact, that the idea that "all should think alike" is both dangerous and anti-democratic, as history shows with plenty of pertinent examples. Since consensus is an absolute unlikely to be achieved in concrete life, a difference must be drawn between "being desirable" and "being essential." All in all, it can be said that it qualifies at most for the former status. The general conclusion is that "consensus is no more than one positive factor that has to be weighed on the scale along with many others."17

It is worth stressing the similarity between Rescher's epistemology and political/social philosophy: they both rest on his skepticism about idealization. In neither case we can get perfect solutions to our problems, short of supposing an - actually unattainable idealization. We have to be fallibilists in epistemology because we are emplaced in suboptimal conditions, where our knowledge is not (and cannot be either) perfected. In other words, we have to be realistic and settle for imperfect estimates (that is, the best we can obtain). In politics, however, the situation is similar. Since we cannot (for the aforementioned reasons) realize a Habermas-style idealized consensus, we must settle for what people will go along with, i.e. "acquiesce in." This may not be exactly what most of us would ideally like but, in any case, if we insist on "perfection or nothing," we shall get a situation very far away from our ideal standards. In the socio-political context, "realism" means settling for "the least of the evils" because, as history teaches, disaster will follow if we take the line that only perfection is good enough.

\section{NOTES}

1. It should be noted that no clear and neat border-line exists between the social and the political realms.

2. N. Rescher (1989), Cognitive Economy, University of Pittsburgh Press, Pittsburgh, 44.

3. N. Rescher (1993), Pluralism, Clarendon Press, Oxford, 9-10.

4. See C. J. Misak (1991), Truth and the End of Inquiry. A Peircean Account of Truth, Oxford, Clarendon Press.

5. N. Rescher, Pluralism, cit., p. 24n. 
6. N. Rescher (1984), The Limits of Science, Berkeley-Los Angeles, University of California Press, 176-8.

7. N. Rescher, Pluralism, cit., 54.

8. Ibid., 101.

9. Ibid., 109.

10. Ibid., 125.

11. Ibid., 158.

12. Obviously the non-traditional Marxism of the Frankfurt School is different from other, more familiar brands of the same doctrine which have been so popular in Europe for many decades. But, no doubt, the typical Marxist utopian quest for perfection and homogeneity is still there.

13. Ibid., 178-9.

14. Ibid., 166.

15. See F. Fukuyama (1992), The End of History and the Last Man, New York, Free Press.

16. N. Rescher, Pluralism, cit., 164-5.

17. Ibid., 199 